\title{
South Africa's contribution in the field of Forensic Odontology - A textbook review
}

SADJ August 2021, Vol. 76 No. 7 p422 - p423

LM Sykes', L Robinson ${ }^{2}$

Editor: Hrvoje Brkić

Co-editors: Rüdiger Lessig,

Ricardo Henrique Alves da Silva,

Vilma Pinchi, Patrick Thevissen

Publisher: Naklada Slap

ISBN: 978-953-191-940-1

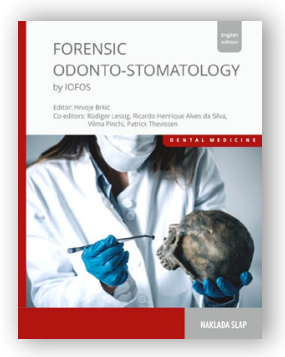

This textbook represents an up-to-date, comprehensive compilation of the field of Forensic Odontology. The chapters have been uniquely structured to take the reader through all aspects of this discipline in a methodical and logical approach. Authors for each section were carefully selected as being internationally recognised experts and renowned amongst their peers in their particular field of Forensic Odontology.

The material in this textbook is presented in a manner that is both interesting and clear for novices in the discipline, while at the same time offering highly informative, cutting-edge information for experts practising Forensic Odontology. The book begins with a chronology of the origin of Forensic Odontology dating back to 1477, using intriguing real-life cases to set the theme for the rest of the book.

\footnotetext{
Author affiliations:

1. Leanne M Sykes: BSc, BDS, MDent, Dip Research Ethics (IRENSA), Dip ESMEA (University of Dundee), DipOdont (Forensic Odontology), Department of Prosthodontics, School of Dentistry, Faculty of Health Sciences, University of Pretoria, Pretoria, South Africa.

ORCID Number: 0000-0002-2002-6238

2. Liam Robinson: $B C h D, P D D$ (Maxillofacial Radiology), $P D D$ (Forensic Odontology), Department of Oral Pathology and Oral Biology, School of Dentistry, Faculty of Health Sciences, University of Pretoria, Pretoria, South Africa. ORCID Number: 0000-0002-0549-7824

Corresponding author: Leanne M Sykes

Department of Prosthodontics, School of Dentistry, Faculty of Health Sciences, University of Pretoria, Pretoria, South Africa.

Email: leanne.sykes@up.ac.za

Author contributions:

1. Leanne M Sykes: Co-author $-50 \%$

2. Liam Robinson: Co-author $-50 \%$
}

Chapter 2 was written by Professor Herman Bernitz (Department of Oral Pathology and Oral Biology, University of Pretoria) and is not for the faint-hearted. He presents a finely detailed and vividly illustrated working guide on mortuary procedures associated with victim identification. One cannot read this chapter without having a true admiration for him and his Forensic Odontology team at the University of Pretoria.

The book then takes the reader through the practical aspects of forensic dental identification, including dental charting, radiology and photography. It then delves into the scientific aspects of DNA analysis and dental age estimation. A section is dedicated to dental profiling, heredity and acquired dental anomalies, and teeth in an-

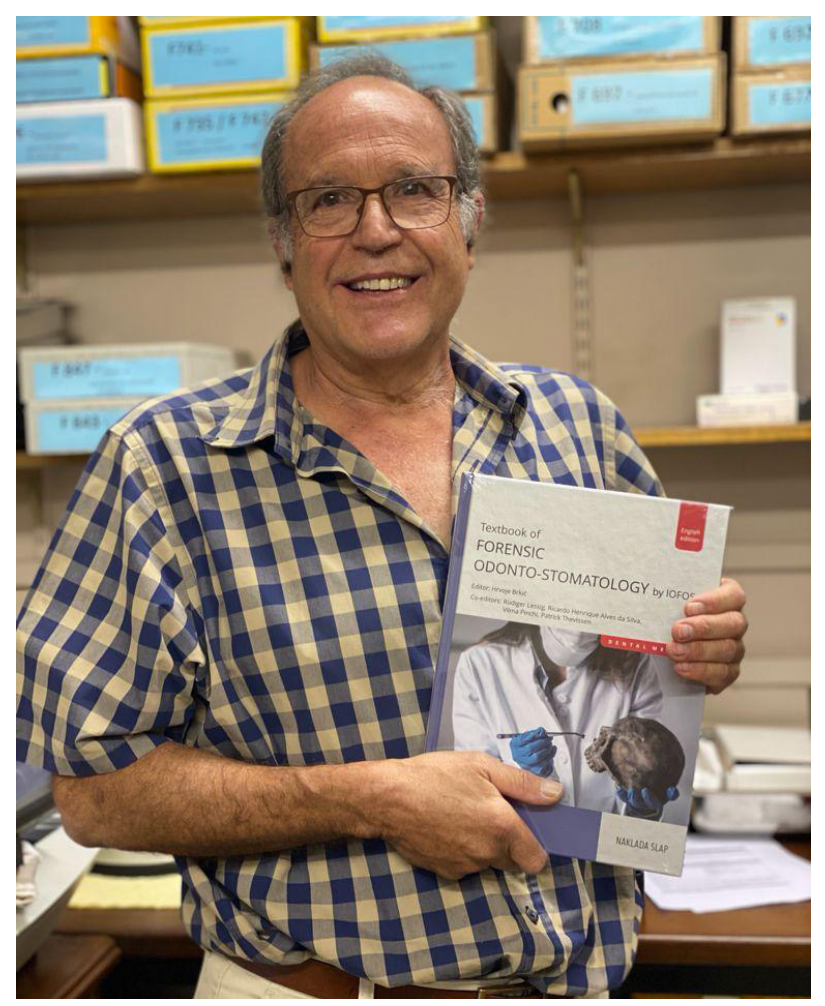

Professor Herman Bernitz (BChD, Dip (Odont), MSc, PhD.) holding a copy of the Textbook of Forensic Odonto-Stomatology. 
cestry, including their use in gender determination. One chapter has been included on cheiloscopy and rugoscopy - the analysis of unique lip and the palatal features in victim identification, a concept similar to more commonly used fingerprinting methods.

The following four chapters are dedicated to victims of mass disasters, human abuse and facial trauma. Once again Professor Bernitz compiled the well-researched chapter on bitemark collection and analysis, based on his years of experience and international regard in this intriguing and often much-deliberated field of Forensic Odontology. It is a discipline that has developed from humble beginnings using only macroscopic analysis, to the cutting edge addition of metric, microscopic and more recently three-dimensional analyses.

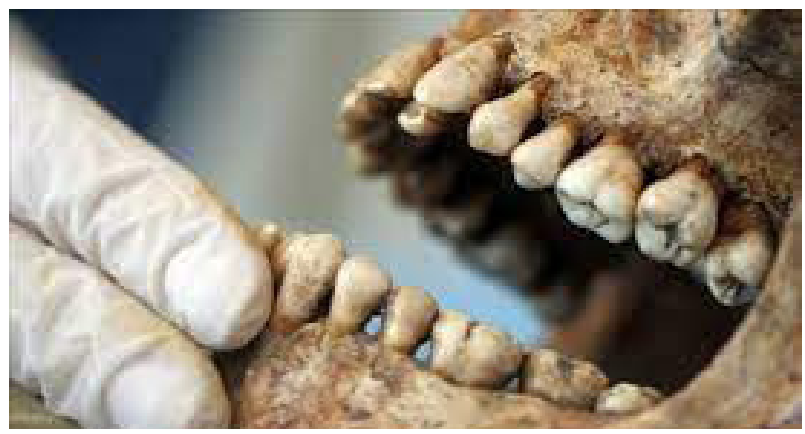

These chapters on human violations lead well into the next sections covering expert witness presentation, the use of information technology, and quality assurance in Forensic Odontology. They are a reminder to all clinicians on the importance of keeping accurate and thorough dental records, and the necessity to safeguard these in the event that they may be needed at some stage in the future. It is also a reminder to resist the urge to elaborate with personal emotions and opinions in patients' files and records, as only verifiable and factually correct information is acceptable in a court of law.

The penultimate chapter covers the fascinating art and science of facial approximation and reconstruction. The authors are so confident that this textbook will inspire and stimulate everyone who reads it to delve deeper into the fascinating field of Forensic Odontology, that they dedicated a final section on how one can further their education and qualifications in Forensic Odontology.

If you are interested in the field of Forensic Odontology, we strongly recommend reading the "Textbook of Forensic Odonto-Stomatology by IOFOS". We are fully confident that once you pick up the book you will be so captivated that you will not be able to put it down until you have bitten into and devoured every single page. Congratulations Professor Bernitz on this momentous achievement and your contributions in the field of Forensic Odontology!

\section{Do the CPD questionnaire on page 435}

The Continuous Professional Development (CPD) section provides for twenty general questions and five ethics questions. The section provides members with a valuable source of CPD points whilst also achieving the objective of CPD, to assure continuing education. The importance of continuing professional development should not be underestimated, it is a career-long obligation for practicing professionals.

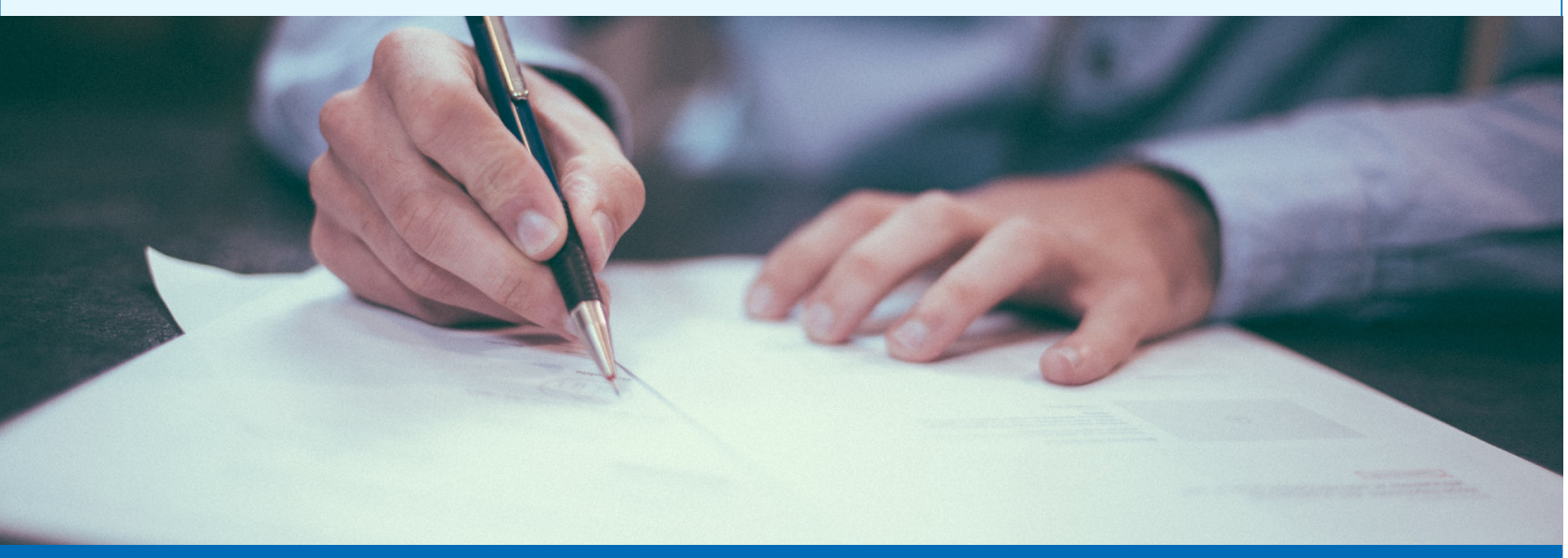

\section{Online CPD in 6 Easy Steps}

1 Go to the SADA website www.sada.co.za.

2 Log into the 'member only' section with your unique SADA username and password.

3 Select the CPD navigation tab.

4 Select the questionnaire that you wish to complete.

5 Enter your multiple choice answers. Please note that you have two attempts to obtain at least $70 \%$.

$6 \quad$ View and print your CPD certificate. 